\title{
Co-composting of sewage sludge:fats mixtures and characteristics of the lipases involved
}

Teresa Gea, Pau Ferrer, Gregorio Alvaro, Francisco Valero, Adriana Artola and Antoni Sánchez*

Departament d'Enginyeria Química, ETSE, Universitat Autònoma de Barcelona

08193-Bellaterra (Barcelona, Spain).

*Corresponding Author:

Dr. Antoni Sánchez Ferrer

E-mail address: antoni.sanchez@uab.cat

Fax: 34-935812013 


\begin{abstract}
Co-composting of sewage sludge and animal fat mixtures was studied in order to determine the possibility of using this technology to recycle fat-enriched wastes. A maximum fat content of $30 \%$ in fat:sludge mixtures is recommended to achieve the international sanitation requirements on compost quality and to avoid an excessive thermophilic composting time. Under these conditions a fat content reduction of $85 \%$ was achieved. Biological activity was highly dependent on the moisture content as shown by the respiratory quotient values. Moisture content is a critical control factor because of the hydrophobic nature of fats and should be maintained above $40 \%$ in the composting of fats. Biological indices of the compost obtained after 69 days of process (Maturity Grade: IV; Respiration Index: 1.1 $\mathrm{mg} \mathrm{O}_{2}$ consumed per g organic matter and hour) indicated a high stability and maturity degree of the material. Lipases responsible for fat hydrolysis were monitored during the composting process and a sample from the thermophilic period was characterized in terms of stability in front of $\mathrm{pH}$ and temperature. Optimal conditions for lipase stability were found at $38.3^{\circ} \mathrm{C}$ and $\mathrm{pH} 7.97$, however the maximum lipolytic activity was observed at thermophilic temperatures. Lipases from the thermophilic period were purified by anion exchange chromatography and visualised by SDS-PAGE. Two major bands were observed at molecular weights of 29 and $62 \mathrm{kDa}$. These bands could not be identified precisely by $\mathrm{N}$-terminal sequence analysis.
\end{abstract}

Key words: Aerobic processes, Biodegradation, Waste Treatment, Fat, Lipase, Respiration Index. 


\section{Introduction}

Among the available technologies to recycle organic solid wastes, composting is often presented as a low-technology and low-investment process to convert organic solid wastes to an organic fertilizer known as compost. Composting is a biotechnological process by which different microbial communities initially degrade organic matter into simpler nutrients and, in a second stage, complex organic macromolecules such as humic acids are formed [1]. Composting is an aerobic process, which requires oxygen for microbial biodegradation, optimal moisture and porosity [2]. Temperature, oxygen and moisture content are often selected as the control variables in the composting process, jointly with other chemical, biochemical or microbiological properties [3-6].

Fats and oils are essentially triglycerides consisting of straight-chain fatty acids attached, as esters, to glycerol. Fatty acids profile can vary considerably since they can differ in chain length and may be saturated or unsaturated [7]. The biodegradation of a fat begins with an enzymatic hydrolysis of the ester bond carried out by lipases, followed by the consumption of glycerol and the betaoxidation of fatty acids [8]. Fats are, on the other hand, one of the major components of organic matter in wastewater [9] and solid wastes, especially those coming from food industry [10,11].

Different works report biological treatment of fats, however, biodegradability of lipids is generally considered as largely limited by unfavourable physico-chemical properties, such as their insolubility in water [12]. The biological treatment of fats under thermophilic conditions is expected to be advantageous due to favourable changes in the physical properties of these hydrophobic compounds [13]. In this sense, composting, which is characterized by the rapid development of a thermophilic initial stage, can be an alternative to treat effectively fats and oils. Composting of fats is nevertheless difficult due to the nutritional lacks of fats, especially low contents of nitrogen and phosphorous in relation to a high carbon content. This usually implies that a co-substrate is necessary to compensate the $\mathrm{C} / \mathrm{N}$ ratio of the initial mixture, in a process called co-composting. Among the substrates cocomposted with fats, different types of sludge are used, because of its typical low $\mathrm{C} / \mathrm{N}$ ratio. Thus, 
olive mill wastewater [11,14], sewage sludge [7] and municipal solid wastes [15] have been used in the co-composting of fats or fat-enriched wastes.

Several aspects in the composting of wastes with high fat content have been studied. In general, routine composting parameters show that co-composting of these wastes is possible with low percentages of fats $(5-15 \%)$ in the initial mixture [16-18], causing a longer thermophilic phase that is attributed to the high chemical energy content of fats [19]. On the other hand, values of lipid degradation reported are usually high, within $80-90 \%[17,18,20]$. Other authors have reported studies on the physico-chemical parameters showing the importance of the control of $\mathrm{pH}[21]$, whereas in other works some microbiological studies are carried out, concluding that there is not a clear correlation between the microbial populations isolated during the different phases of the process with their role in the degradation of fats $[10,20]$ and that probably some global biological activity indicators such as respiration profiles are more useful [11].

However, other crucial aspects such as the presence and properties of lipases involved in the composting of fat-enriched wastes have been only qualitatively studied or remain unclear. To our knowledge, although some few works have reported qualitative values of enzymatic activities during composting [22-27], the characteristics and role of lipases in the composting of high-content fat wastes have not been studied.

The objectives of this work are: i) to study the behaviour of a co-composting process at laboratory scale using sewage sludge as a basic substrate (a commonly composted waste) amended with different ratios of fats in order to determine the optimal ratio fat:sludge in terms of composting time and efficiency, ii) the determination and evaluation of biological indices in the co-composting process at pilot scale for the optimal fat:sludge ratio, iii) to study the properties of the lipases implied in the hydrolysis of fats, especially those related to their stability and optimal conditions for enzymatic activity, and iv) to identify the main microbial lipases involved in the co-composting of sewage sludge and fats. 


\section{Materials and Methods}

\subsection{Composting Materials}

Animal fat (Trg Sebo Fancy, KAO Corporation S.A., Spain) coming from a cow slaughterhouse was added to anaerobically digested sewage sludge from the wastewater treatment plant of Granollers (Barcelona, Spain) in different amounts. Wood chips from a local carpentry were used as bulking agent added to the sludge-fat mixture in a volumetric ratio 1:1, which was previously found as optimal for sewage sludge composting at laboratory scale [28]. Main characteristics of composted materials are summarized in Table 1. The long chain fatty acid (LCFA) profile of animal fat is presented in Table 2 .

\subsection{Composting experiments at laboratory scale}

Preliminary co-composting experiments were carried out using sewage sludge as basic substrate and increasing amounts of fat ranging from 0 to $80 \%$ of total dry weight. In general, fat content could be increased up to $50 \%$ with a thermophilic period maintained for longer times (data not shown). For higher amounts of fat content, however, oxygen diffusion was severely hampered. Moreover, moisture content could not be maintained within the optimal range for composting (40$60 \%$ ). Therefore, a fat content of $50 \%$ (dry basis) was considered as the upper limit for the cocomposting process.

Fat and sludge co-composting process was carried out at laboratory scale to determine the optimal fat content of the mixture (within 0 to $50 \%$ dry basis) in terms of process duration and fat content reduction. Lipolytic activity during the process was also studied. Composting experiments 
were undertaken for 36 days: a control experiment with no fat added to the sludge; sludge with $30 \%$ of total fat content (L30); and sludge with 50\% of total fat content (L50).

The initial characteristics of the mixtures sludge:fat with bulking agent are presented in Table 3. Moisture content was within the recommended range for composting (40-60\%) [2] during the process for all the mixtures.

Laboratory-scale experiments were undertaken using 4.5-1 Dewar® vessels conditioned for composting. A perforated lid was conditioned for temperature monitoring and air supply and a rigid wire net was placed near the bottom of the vessel to separate the composting material from possible leachates.

Pt-100 sensors were used for temperature monitoring placed in the material to have a measuring point at $1 / 2$ of the height of the material in the vessel. Temperature sensors were connected to a data acquisition system (DAS-8000, Desin, Spain) which was connected to a personal computer. The system allows, by means of the proper software (Proasis ${ }^{\circledR}$ Das-Win 2.1, Desin, Spain), the continuous on-line visualisation and registration of the temperature. Oxygen content was measured with a portable oxygen detector (Oxy-ToxiRAE, RAE) with a frequency of 3-7 times a day.

For the co-composting experiments with fat and sludge two replicates were undertaken. The maximum deviation observed between replicates was $10 \%$ for any of the parameters analyzed, which can be considered low in the composting field. In consequence, only the results of one replicate are presented in the Results section.

\subsection{Composting experiments at pilot scale}

Pilot experiment was undertaken in a 100-1 static composter. A plastic mesh was fitted at the bottom of the recipient to support the material and separate it from possible leachates. Several holes were perforated through the walls of the vessel to permit air movement, leachates removal and the 
insertion of different probes. The composter was placed on a scale (BACSA mod. I200) for on-line waste weight monitoring.

Four Pt-100 sensors (Desin mod. SR-NOH) inserted at different points inside the 100-1 tank were used for monitoring the temperature. Temperature average values are presented. Oxygen and $\mathrm{CO}_{2}$ of interstitial air were measured with an oxygen sensor (Sensox, Sensotran, Spain) and a $\mathrm{CO}_{2}$ infrared detector (Sensontran I.R., Sensotran, Spain) respectively. All sensors were connected to a self-made data acquisition system. Oxygen was controlled by means of a feedback oxygen control which automatically supplied fresh air (room temperature) to the reactor by means of a flow meter (Sensotran mod. MR3A18SVVT) to maintain an oxygen concentration above $10 \%$.

\subsection{Respiratory Quotient $(R Q)$}

RQ was calculated as the quotient of $\mathrm{CO}_{2}$ produced and $\mathrm{O}_{2}$ consumed as indicated in Equation $1[29]:$

$R Q=\frac{C O_{2, \text { out }}}{20.9-O_{2, \text { out }}}$

where: RQ, respiratory quotient (dimensionless); $\mathrm{CO}_{2, \text { out }}$, carbon dioxide concentration in the exhaust gases (\%); $\mathrm{O}_{2, \text { out }}$, oxygen concentration in the exhaust gases (\%).

$\mathrm{CO}_{2}$ percentage in inlet air was considered negligible and average $\mathrm{O}_{2}$ concentration in inlet air was $20.9 \%$. RQ is presented as an average of 10 values (100 minutes of measurement).

\subsection{Lipolytic activity}


Lipolytic activity was determined using a commercial kit (Roche/Hitachi LIP num. 1821792) as described by [30]. Briefly, lipases were extracted from $5 \mathrm{~g}$ samples using $50 \mathrm{ml}$ of $400 \mathrm{mM}$ Tris$\mathrm{HCl}$ buffer with $10 \mathrm{mM} \mathrm{CaCl}_{2}$ and adjusted at $\mathrm{pH}$ 8.0, and adding 5\% (w/w) Triton X-100 (Panreac, Barcelona, Spain) to ensure a quantitative extraction of lipases [31]. After 30 minutes of extraction using a magnetic stirrer, supernatant was centrifuged $(30 \mathrm{~min}, 3500 \mathrm{~g})$ and filtered $(0.45 \mu \mathrm{m})$ to remove biomass and solids. This sample was then used for lipolytic activity determination. Standard lipolytic activity assays were run at $30^{\circ} \mathrm{C}$ although other temperatures were used in some occasions. One activity unit was defined as the quantity of enzyme necessary to release $1 \mu \mathrm{mol}$ of fatty acid per min under the described conditions. Lipolytic activity was expressed as activity units per gram of dry matter.

\subsection{Long chain fatty acids (LCFA)}

$50 \mathrm{ml}$ of heptane (99\% purity) were added to $5 \mathrm{~g}$ of sample and mixed for $30 \mathrm{~min}$ to extract LCFA. The suspension was then centrifuged (30 min, 3500g) and the resulting supernatant filtrated through a Millipore Millex-FGS filter $(0.2 \mu \mathrm{m})$. This extract was used for free LCFA determination by gas chromatography. A Perkin-Elmer AutoSystem XL Gas Chromatograph with a flame ionization detector (FID) and a HP Innowax $30 \mathrm{~m}$ x $0.25 \mathrm{~mm} \times 0.25 \mu \mathrm{m}$ column was used. The carrier gas was Helium and a split ratio of 13 was used. An initial temperature of $120^{\circ} \mathrm{C}$ was kept for 1 min; then, it was increased to $250^{\circ} \mathrm{C}$ at $8^{\circ} \mathrm{C} \mathrm{min}^{-1}$, and maintained at that temperature for $7 \mathrm{~min}$. The system was calibrated with different dilutions of a standard mixture of LCFA of concentrations in the range 0-100 $\operatorname{mg~} 1^{-1}$.

\subsection{Effect of temperature and $\mathrm{pH}$ on lipase stability}


A full composite factorial experimental design was carried out to study the combined effect of $\mathrm{pH}$ and temperature on the stability of the lipases extracted from the composting samples. The experimental design consisted of 16 experiments (12 experiments and 4 replications in central points). The levels selected for both variables were: 3 levels for $\mathrm{pH}$ : 5.0, 7.0 and 9.0; and 4 levels for temperature, $30,45,60$ and $75^{\circ} \mathrm{C}$. Residual activity after 1 hour of incubation was selected as the objective function and as a measure of lipase stability. Buffers used for the incubation at the selected pH were: Tris-HCl 1M, pH 9.0; Tris- $\mathrm{HCl} \mathrm{1M,} \mathrm{pH} \mathrm{7.0;} \mathrm{Acetic} \mathrm{acid-sodium} \mathrm{acetate} \mathrm{1M,} \mathrm{pH} \mathrm{5.0.}$

\subsection{SDS-PAGE}

Polyacrylamide gel electrophoresis (PAGE) was performed in $12 \%$ polyacrylamide gels in denaturing conditions as described by [32]. A vertical slab Mini Protean II cell (Bio-Rad, Richmond, CA) was used for electrophoresis. Proteins were visualised by Coomassie staining according to standard procedures. Broad range molecular weight markers for electrophoresis were from Bio-Rad (Richmond, CA, USA).

\subsection{Anion exchange chromatography (AEC)}

All chromatographic steps were run on a Pharmacia FPLC system. Lipase sample was concentrated and dialyzed with an Ultrafree ${ }^{\circledR}-\mathrm{MC}$ filter unit (Millipore), $10 \mathrm{kDa}$ cut-off, using a 5 $\mathrm{mM}$ Tris-HCl buffer ( $\mathrm{pH} 8$ ). The concentrated sample was loaded to a Source ${ }^{\circledR} 15 \mathrm{Q}$ HR5/5 column equilibrated with $20 \mathrm{mM}$ Tris- $\mathrm{HCl}(\mathrm{pH} 8)$, at a flow rate of $1 \mathrm{ml} \mathrm{min}^{-1}$ and $2 \mathrm{ml}$ fractions were collected. To elute proteins, $\mathrm{NaCl}$ concentration was increased from 0 to $1 \mathrm{M}$ in 40 minutes. Lipolytic activity was determined in the fractions collected using the procedure previously described.

\subsection{Amino terminal sequence determination of proteins}


The protein samples were separated by SDS-PAGE and electrotransferred to Immobilon PVDF membranes (Bio-Rad) using a MiniProtean II blotting unit (Bio-Rad). The proteins were visualized by Coomassie following manufacturer's instructions. The protein bands of interest were excised from the membrane and subjected to $\mathrm{N}$-terminal sequence determination using a Beckman LF3000 sequencer.

\subsection{Analytical methods}

Moisture content, total organic matter, $\mathrm{pH}$, conductivity and compost maturity grade (Dewar self-heating test) were determined according to the standard procedures [33]. Lipid content was measured using a standard Soxhlet method using n-heptane as organic solvent [34].

Respiration Index was determined in a static respirometer built according to the original model described by [35] and following the modifications and recommendations given by [33].

\section{Results and Discussion}

\subsection{Laboratory scale experiments}

Figure 1 shows the temperature profiles, the evolution of total fat content and the lipolytic activity during the composting process in the different laboratory scale experiments. Missing data on days 19, 27 and 33 correspond to system failures, with no oxygen control and no data acquisition. As can be observed, control experiment did not reach the thermophilic range of temperatures in the whole composting period which can be attributed to a low chemical energy content found in anaerobically digested sludge [29]. However, temperatures in L30 and L50 experiments reached the thermophilic 
range (temperatures above $45^{\circ} \mathrm{C}$ ), and temperatures above $55^{\circ} \mathrm{C}$ were maintained for an average period of 6.6 days for L30 and 10 days for L50. Although the international requirements on compost sanitation (temperature above $55^{\circ} \mathrm{C}$ for a total period of 2 weeks) were not completely fulfilled for $\mathrm{L} 30$ and L50 experiments [36] it is likely that composting of these mixtures at large scale will ensure a complete sanitation of compost, because of the thermal inertia effect found in large composting masses [2]. The strategy of co-composting a high energy waste such as fats or fat-enriched wastes with a low energy waste such as certain sludges can be recommended in order to achieve the sanitation of compost. As expected, thermophilic phase duration was significantly longer for L50 (Fig. 1c). Thus, although mixtures with fat content up to $50 \%$ (dry basis) can be composted, a lower fat content can be recommended if excessively long composting periods are to be avoided (e.g. in full-scale facilities).

A significant fat reduction was observed in all the experiments (Fig. 1) although a remaining fat fraction was found in all the final products. It is possible that fat present in sludge contents a recalcitrant fraction of non biodegradable lipidic substances, which are referred to be trapped in the humic structure of composted sludge [37]. Nevertheless, a detailed chemical composition of sludge was not available. Table 3 shows total dry weight and total fat reductions. As can be observed, dry weight reduction was similar for L30 and L50 (near 40\%), and higher than that of the control experiment (14\%). The higher fat content reduction in a relative basis was for L30 (85\%) while L50 presented a lower efficiency in fat degradation (68\%). However, it is interesting to mention that absolute fat reduction was 25, 174 and $283 \mathrm{~g}$ for control, L30 and L50 experiments, showing the high capacity of a composting environment for fat degradation. It must be pointed that these results are obtained with an initial fat content much higher than those previously reported [16-18].

Lipolytic activity (Fig. 1) was higher for L30 experiments, which is also in accordance with a higher fat content reduction. In all experiments lipolytic activity tended to increase at the beginning of the process and to reach a final plateau (Fig. 1a to 1c).

The concentration of the main long chain fatty acids is an indicator of the lipolytic activity. LCFAs were not detected in the control experiment and detected only the first 11 days in L30. In L50, 
LCFAs concentration increased until day 22 following the same pattern found in lipolytic activity, to decrease to negligible values at the end of the process (Fig. 2).

From these results, it is probable that the addition of fats to a $30 \%$ total content results in a balanced environment for microorganisms responsible of organic matter degradation, and the necessary lipolytic activity, the consumption of LCFA and the degradation of the rest of organic matter are not limited, which provoked the highest lipolytic activity or a higher rate of enzymatic hydrolysis (Fig. 1) and no accumulation of LCFA. On the contrary, with a higher fat content (50\%) it seems that the microbial activity and lipolytic activity are hampered, which can be attributed to a combination of different phenomena such as nutrient limitation, insufficient moisture or low oxygen diffusion [21]. In particular, it can be observed in Table 3 that the high $\mathrm{C} / \mathrm{N}$ ratio found for L50 experiment is not in the range of optimal conditions for a successful composting process [2].

\subsection{Pilot scale composting}

A co-composting experiment with the recommended maximum fat content determined at laboratory scale (30\%) was carried out at pilot scale (P30) to monitor the most significant biological activity parameters and to obtain an amount of compost that permitted to study lipase characteristics. Table 3 presents the initial parameters of the mixture which were again in the optimal range for composting [2]. The LCFA profile of the fat content in the mixture, very similar to that of animal fat, is presented in Table 2 .

Figure 3 shows the temperature, oxygen and $\mathrm{CO}_{2}$ profiles obtained in the co-composting process, and the moisture content evolution. Periods with no data in Figure 3 (days 4 and 11) correspond to system failures with no oxygen control and no data acquisition. As can be observed, the process followed the typical temperature composting profile, with a thermophilic temperature reached at the first days of composting and maintained during a long period (temperature above $55^{\circ} \mathrm{C}$ for a total period of 14 days). Therefore, it is confirmed that increasing the composting scale, the sanitation 
requirements are fulfilled [36]. As can be observed in Table 3, total dry weight and total fat reduction in P30 experiment were similar to those found in the L30 experiment.

From day 28 to 33 and from day 38 to 42 temperature decreased due to the low moisture content reached (Fig. 3a). High amounts of leachate were produced during the process due to the high hydrophobic nature of fats which reduces the water holding capacity of the organic matrix (the total amount of leachate accounted for $25 \%$ of the initial weight of material in the composter). This fact produced a reduction of the moisture content of the composting material and limiting values for microbial activity were reached $(<40 \%)$, which produced a temperature decrease. When the material in the reactor was watered to reach a moisture content above $45 \%$, the microbial activity and thus, temperature, recovered quickly (Fig. 3a). When fat content was below 15\% (from day 40) the leachate generation decreased, which reduced the water requirements to maintain the optimal moisture level. Nevertheless, no fats were detected in leachate coming from the composting experiments.

Oxygen content in interstitial air was maintained above $10 \%$ along the process, ensuring aerobic conditions (Fig. 3b). Respiratory Quotient (RQ) is the relation between $\mathrm{CO}_{2}$ produced and $\mathrm{O}_{2}$ consumed. Its value is approximately 1 under aerobic conditions although it depends on the oxidation degree of the organic matter to be degraded (it is around 1 for carbohydrates-like materials). Average value of RQ was $0.98 \pm 0.21$ (Fig. 3b), whereas the values of RQ obtained in previous composting experiments using only sewage sludge were $1.09 \pm 0.08$ [29]. This is in accordance with the fact that fats are reduced carbon compounds, although the expected value of RQ should be probably lower according to the high proportion of fats added to sludge. Other studies have reported a similar RQ decrease when fats were added to municipal solid waste (RQ decreased from 0.95 to 0.87 ) [38].

In relation to $\mathrm{CO}_{2}$ production, a reduction was observed from day 15 to 30 (Fig. 3b), which is simultaneous with the lowest values of moisture content detected in the composting process (Fig. 3a). It has been reported that microorganisms under stress conditions may reduce the $\mathrm{CO}_{2}$ production using oxygen mainly for maintenance operations [39,40]. This hypothesis could explain the reduction 
observed in $\mathrm{CO}_{2}$ emissions and it is confirmed by the fact that no significant fat reduction was observed from day 22 to 32 (see Fig. 4b).

Lipolytic activity and total fat content are presented in Figures $4 \mathrm{a}$ and $4 \mathrm{~b}$ respectively. Fat reduction was lower in the first two weeks of process ( $7.5 \%$ of total fat reduction), probably due to the degradation of other more biodegradable molecules delaying lipolytic activity (Fig. 4a). Moreover lipases could have been adsorbed on interphases [41] and released at lower fat contents (Fig. 4a and $4 b)$.

Figure $4 \mathrm{~b}$ also shows the different LCFA concentrations measured during the composting process. The main organic acids detected (oleic acid, stearic acid and palmitic acid) followed the same profile. Their concentration slightly increased during the first 20 days of process to decrease thereafter until the end of the experiments, when they could not be detected. The initial accumulation of LCFA (Fig. 4b) is an evidence that some lipolytic activity was present in the composting matrix although it was not detected (Fig. 4a), which could be due to an insufficient extraction procedure. The oleic acid concentration detected was 4-7 times higher than palmitic acid concentration and 4-15 times higher than stearic acid concentration. As these ratios do not correspond to the initial composition (Table 2) it seems clear that there is a different biodegradation pattern for the LCFA present in the composted waste, presenting oleic acid a low biodegradability when compared to other shorter and saturated LCFA such as palmitic and stearic acid.

Maturity and stability tests (Self-heating Test and Respiration Index) were carried out in the final period of the process. Respiration index was determined after 3 weeks of process, when a considerable degradation was observed, and self-heating test was undertaken with samples from the mesophilic maturation stage at the end of process. Results are presented in Table 4. After 69 days of process the material presented a high maturation and stabilisation degree, which is in accordance with requirements for compost application to soil $[3,33]$.

\subsection{Characteristics of lipases}


As stated before, the lipolytic activity was followed during the co-composting process (Fig. 4a). In addition to standard measures at $30^{\circ} \mathrm{C}$, a thermophilic temperature $\left(50^{\circ} \mathrm{C}\right)$ was selected for lipolytic activity determination to obtain activity values according to real temperature conditions in the composting environment. Lipolytic activity detected at $50^{\circ} \mathrm{C}$ was significantly higher than that detected at $30^{\circ} \mathrm{C}$ but both activities followed the same pattern (Fig. 4a). Once it was detected, activity increased progressively to decrease on day 41 when moisture content reached values limiting for microbial activity and temperature decreased. Once the moisture content was recovered, lipolytic activity increased again. Again, this fact seems to confirm the intimate relationship between adequate moisture content and the microbiological activity related to the enzyme production.

A lipase sample extracted on day 34 of process was used to determine the properties and characteristics of the enzyme. Day 34 corresponded to the thermophilic period of the composting process and a high lipolytic activity was detected. Figure 5 shows the lipolytic activity of the sample at different temperatures of the activity test. As can be observed, activity was higher for thermophilic temperatures, which is in agreement with temperatures found in the composting environment at the moment of sampling.

Additionally, the combined effect of $\mathrm{pH}$ and temperature $(\mathrm{T})$ on lipases stability was determined by means of a factorial experimental design. From the experimental design results (normalized data) the next equation was obtained to describe lipase stability (expressed as residual activity):

$$
\text { Residual Activity }(\%)=114.2-49.2 \mathrm{~T}+28.0 \mathrm{pH}-42.9 \mathrm{~T}^{2}-35.6 \mathrm{pH}^{2}-10.3 \mathrm{TpH}
$$

Figure 6 shows the response surface obtained from the above equation. The lipase presented a high stability for most of the conditions tested, as can be deduced from the independent term over $100 \%(114.2 \%)$, which indicates a reactivation of the enzyme under the incubation conditions. It is evident that some of the conditions tested in the experimental design contributed to the lipase activation. The interaction term $\mathrm{T}-\mathrm{pH}$ on the equation 1 indicated a simultaneous effect on lipase 
stability of both factors. The lipase sample was more sensitive to the effect of temperature than that of $\mathrm{pH}$ (temperature coefficients significantly higher than $\mathrm{pH}$ coefficients). The value of coefficients indicated that high values of temperature had a negative effect on stability whereas alkaline values of pH presented a positive effect on stability. These effects can also be observed in Figure 6. Optimal conditions for stability were found at $38.3^{\circ} \mathrm{C}$ and $\mathrm{pH} 7.97$ (136.5\% residual activity for optimal conditions). Optimal $\mathrm{pH}$ corresponded to the values of the composting experiments, although it was expected to find an optimal value of temperature within the thermophilic range according to composting conditions. However, our results are in agreement with stability results for other lipase not related to composting field [42] and other composting enzymes [43], where optimal values are found within the mesophilic range of temperatures.

\subsection{Lipase identification}

The sample used for the lipase stability study (thermophilic period of P30 experiment) was purified by anion exchange chromatography and a subfraction with lipolytic activity was eluted at a concentration of $\mathrm{NaCl} 0.6 \mathrm{M}$ (data not shown). This procedure permitted to remove non-lipolytic proteins that are usually present in complex samples from composting environments or sludges [31,41]. SDS-PAGE of this fraction is presented in Figure 7. Two major bands were observed corresponding to molecular weights of 29 and $62 \mathrm{kDa}$. To identify these proteins, N-terminal sequence was determined on each of these bands. The N-terminal sequence of $62 \mathrm{kDa}$ band could not be determined precisely, probably due to an insufficient amount of protein transferred in the blotting unit. This band may correspond to a fungi lipase since similar molecular weights are found in lipases produced by yeasts and fungi [44,45]. The first amino acid of the N-terminal sequence of the $29 \mathrm{kDa}$ band could not be identified. The following amino acid sequence was FELPALP or IELPALP. These sequences were analysed for similarities to other sequences in the National Center for Biotechnology Information (NCBI) database and no correspondences were found for known lipases. It is then likely 
that some non-identified microorganisms are responsible for the production of extracellular lipases in the composting environment. 


\section{Conclusions}

Several conclusions can be obtained from this work:

1) Co-composting process of fats and sludge can be successfully carried out to obtain a sanitized and stabilized product. Addition of fat content up to $50 \%$ is possible although a maximum fat content of $30 \%$ is recommended to achieve a high fat content reduction (85\%) and to avoid long composting periods at full-scale facilities.

2) Fat-enriched wastes can be added to low energy content wastes to fulfil the international requirements on compost sanitation. From this point of view, co-composting strategies are of special interest for plant managers.

3) Moisture content is a critical control factor in the composting of fat-enriched wastes, since it determines the biological activity of the process, as it is observed from the respiratory quotient and lipolytic activity.

4) Lipase from thermophilic composting environment showed a high stability for mesophilic values of temperature and slightly alkaline values of $\mathrm{pH}$, however, the maximum lipolytic activity was observed at thermophilic temperature.

5) Major lipases involved in the composting of sludge:fat mixture could not be identified by Nterminal sequence analysis. Further research is needed in the field of enzyme identification in composting environments.

\section{Acknowledgments}

The authors wish to thank Inma León for her collaboration in the development of this work. Financial support was provided by the Spanish Ministerio de Ciencia y Tecnología (Project REN200300823). 


\section{References}

[1] Hsu, J., Lo, S., 1999. Chemical and spectroscopic analysis of organic matter transformations during composting of pig manure. Environ. Pollut. 104, 189-196.

[2] Haug, R.T., 1993. The Practical Handbook of Compost Engineering. Lewis Publishers, Boca Raton, FL.

[3] Scaglia, B., Tambone, F., Genevini, P., Adani, F., 2000. Respiration index determination: Dynamic and static approaches. Compost Sci. Util. 8, 90-98.

[4] Liang, C., Das, K.C., McClendon, R.W., 2003. The influence of temperature and moisture contents regimes on the aerobic microbial activity of a biosolids composting blend. Bioresource Technol. 86, 131-137.

[5] Saviozzi, A., Cardelli, R., Levi-Minzi, R., Riffaldi, R., 2004. Evolution of biochemical parameters during composting of urban wastes. Compost Sci. Util. 12, 153-160.

[6] Tang, J.C., Kanamori, T., Inoue, Y., Yasuta, T., Yoshida, S., Katayama, A., 2004. Changes in the microbial community structure during thermophilic composting of manure as detected by the quinone profile method. Process Biochem. 39, 1999-2006.

[7] Wakelin, N.G., Forster, C.F., 1997. An investigation into microbial removal of fats, oils and greases. Bioresource Technol. 59, 37-43.

[8] Lalman, J.A., Bagley, D.M., 2000. Anaerobic degradation and inhibitory effects of linoleic acid. Wat. Res. 34, 4220-4228.

[9] Saatci, Y., Arslan, E.I., Konar, V., 2001. Removal of total lipids and fatty acids from sunflower oil factory effluent by UASB reactor. Bioresource Technol. 87, 269-272.

[10] Galli, E., Pasetti, L., Fiorelli, F., Tomati, U., 1997. Olive-mill wastewater composting: microbiological aspects. Waste Manage. Res. 15, 323-330. 
[11] Mari, I., Ehaliotis, C., Kotsou, M., Balis, C., Georgakakis, D., 2003. Respiration profiles in monitoring the composting of by-products from the olive oil agro-industry. Bioresource Technol. 87, 331-336.

[12] Lefebvre, X., Paul, E., Mauret, M., Baptiste, P., Capdeville, B., 1998. Kinetic characterization of saponified domestic lipid residues aerobic biodegradation. Wat. Res. 32, 3031-3038.

[13] Becker, P., Koster, D., Popov, M.N., Markossian, S., Antranikian, G., Markl, H., 1999. The biodegradation of olive oil and the treatment of lipid-rich wool scouring wastewater under aerobic thermophilic conditions. Wat. Res. 33, 653-660.

[14] Vlyssides, A.G., Bouranis, D.L., Loizidou, M., Karvouni, G., 1996. Study of a demonstration plant for the co-composting of olive-oil-processing wastewater and solid residue. Bioresource Technol. 56, 187-193.

[15] Lemus, G.R., Lau, A.K., 2002a. Biodegradation of lipidic compounds in synthetic food wastes during composting. Canadian Biosystems Eng. 44, 33-39.

[16] Filippi, C., Benidi, S., Levi-Minzi, R., Cardelli, R., Saviozzi, A., 2002. Co-composting of olive oil mill by-products: chemical and microbiological evaluations. Compost Sci. Util. 10, 63-71.

[17] Lemus, G.R., Lau, A.K., 2002b. Effect of carbon availability on greenhouse gases emissions and nitrogen conservation during high rate composting. In: Michel, F.C., Rynk, R.F., Hoitink, H.A.J. (Eds.). Proceedings of the 2002 International Symposium Composting and Compost Utilization. JG Press, Emmaus, p. 833-844.

[18] García-Gómez, A., Roig, A., Bernal, M.P., 2003. Composting of the solid fraction of olive mill wastewater with olive leaves: organic matter degradation and biological activity. Bioresource Technol. 86, 59-64.

[19] Nakano, K., Matsumura, M., 2001. Improvement of treatment efficiency of thermophilic oxic process for highly concentrated lipid wastes by nutrient supplementation. J. Biosci. Bioeng. 92, $532-538$. 
[20] Baeta-Hall, L., Saagua, M.C., Bartolomeu, M.L., Anselmo, A.M., Rosa, M.F., 2005. Biodegradation of olive oil husks in composting aerated piles. Bioresource Technol. 96, 69-78.

[21] Sasaki, N., Suehara, K.I., Kohda, J., Nakano, Y., Yang, T., 2003. Effects of C/N ratio and pH of raw materials on oil degradation efficiency in a compost fermentation process. J. Biosci. Bioeng. 96, 47-52.

[22] Wong, J.W.C., Fang, M., 2000. Effects of lime addition on sewage sludge composting process. Wat. Res. 34, 3691-3698.

[23] Tiquia, S.M., Wan, J.H.C., Tam, N.F.Y., 2001. Extracellular enzyme profiles during cocomposting of poultry manure and yard trimmings. Process Biochem. 36, 813-820.

[24] Tiquia, S.M., Wan, J.H.C., Tam, N.F.Y., 2002. Microbial population dynamics and enzyme activities during composting. Compost Sci. Util. 10, 150-161.

[25] Ryckeboer, J., Mergaert, J., Coosemans, J., Deprins, K., Swings, J., 2003. Microbiological aspects of biowaste during composting in a monitored compost bin. J. Appl. Microbiol. 94, 127137.

[26] Charest, M.H., Antoun, H., Beauchamp, C.J., 2004. Dynamics of water-soluble carbon substances and microbial populations during the composting of de-inking paper sludge. Bioresource Technol. 91, 53-67.

[27] Peláez, C., Mejía, A., Planas, A., 2004. Development of a solid phase kinetic assay for determination of enzyme activities during composting. Process Biochem. 39, 971-975.

[28] Gea, M.T., Artola, A., Sánchez, A., 2003. Application of experimental design technique to the optimization of bench-scale composting conditions of municipal raw sludge. Compost Sci. Util. $11,321-329$.

[29] Gea, M.T., Barrena, R., Artola, A., Sánchez, A., 2004. Monitoring the biological of the composting process: oxygen uptake rate (OUR), Respirometric Index (RI), and Respiratory Quotient. Biotechnol. Bioeng. 88, 520-527. 
[30] López, N., Pérez, R., Vázquez, F., Valero, F., Sánchez, A., 2002. Immobilization of different Candida rugosa lipases by adsorption onto polypropylene powder. Application to chiral synthesis of ibuprofen and trans-2-phenyl-1-cyclohexanol esters. J. Chem. Technol. Biotechnol. $77,175-182$.

[31] Gessesse, A., Dueholm, T., Petersen, S.B., Nielsen, P.H., 2003. Lipase and protease extraction from activated sludge. Wat. Res. 37, 3652-3657.

[32] Laemmli, U.K., 1970. Cleavage of structural proteins during the assembly of the head of bacteriophage T4. Nature. 227, 680-685.

[33] U.S. Department of Agriculture and U.S. Composting Council, 2001. Test methods for the examination of composting and compost. Edaphos International, Houston, TX.

[34] U.S. Environmental Protection Agency, 1998. Method 9071B. URL: http://www.epa.gov/SW846/pdfs/9071b.pdf.

[35] Ianotti, D.A., Pang, T., Toth, B.L., Elwell, D.L., Keener, H.M., Hoitink, H.A.J., 1993. A quantitative respirometric method for monitoring compost stability. Compost Sci. Util. 1, 52-65.

[36] U.S. Environmental Protection Agency, 1995. A Guide to the Biosolids Risk Assessments for the EPA Part 503 Rule. URL: http://www.epa.gov/owm/mtb/biosolids/503rule/.

[37] Reveille, V., Mansuy, L., Jarde, E., Garnier-Sillam, E., 2003. Characterisation of sewage sludge-derived organic matter: lipids and humic acids. Org. Geochem. 34, 615-627.

[38] Weppen, P., 2001. Process calorimetry on composting of municipal organic wastes. Biomass Bioenerg. 21, 289-299.

[39] Priess, J.A., Fölster, H., 2001. Microbial properties and soil respiration in submontane forest of Venezuelian Guyana: characteristics and response to fertilizer treatments. Soil Biol. Biochem. 33, 503-509.

[40] Dilly, O., 2003. Regulation of the respiratory quotient of soil microbiota by availability of nutrients. FEMS Microbiol. Ecol. 43, 375-381. 
[41] Boczar, B.A., Forney, L.J., Begley, W.M., Larson, R.J., Federle, T.W., 2001. Characterization and distribution of esterase activity in activated sludge. Wat. Res. 35, 4208-4216.

[42] López, N., Pernas, M.A., Pastrana, L.M., Sánchez, A., Valero, F., Rúa, M.L., 2004. Reactivity of pure Candida rugosa lipase isoenzymes (Lip1, Lip2 and Lip3) in aqueous and organic media. Influence of the isoenzymatic profile on the lipase performance in organic media. Biotechnol. Prog. 20, 65-73.

[43] Kim, T.I., Jeon, K.H., Ham, J.S., Yang, C.B., Chung, I.B., Kim, M.K., Kim, K.N., 2004. Isolation and characterization of cellulose secreting bacterium from cattle manure: application to composting. Compost Sci. Util. 12, 242-248.

[44] Sánchez, A., Ferrer, P., Serrano, A., Pernas, M.A., Valero, F., Rúa, M.L., Casas, C., Solà, C., 1999a. Characterization of the lipase and esterase multiple forms in an enzyme preparation from a Candida rugosa pilot-plant scale fed-batch fermentation. Enzyme Microb. Technol. 25, 214223.

[45] Sánchez, A., Ferrer, P., Serrano, A., Valero, F., Solà, C., Pernas, M., Rúa, M.L., FernándezLafuente, R., Guisán, J.M., De la Casa, R.M., Sinisterra, J.V., Sánchez-Montero, J.M., 1999b. A controlled fed-batch cultivation for the production of new crude lipases from Candida rugosa with improved properties in fine chemistry. J. Biotechnol. 69, 169-182. 


\section{Tables}

Table 1. Main characteristics of the composted materials.

\begin{tabular}{lccc}
\hline Parameter & Sewage Sludge & Wood Chips & Animal Fat \\
\hline Moisture (\%) & 72.7 & 5.0 & $<1$ \\
\hline Dry Matter (\%) & 27.3 & 95.0 & $>99$ \\
\hline Total Organic Matter (\% dry basis) & 61.5 & 99.4 & $>99$ \\
\hline Fat content (\% dry basis) & & & $>99$ \\
\hline $\mathrm{N}-$ Kjeldhal (\% dry basis) & 13.0 & & $<0.02$ \\
\hline C/N ratio & & 0.1 & $>4000$ \\
\hline
\end{tabular}


Table 2. Long chain fatty acids profile of the animal fat used as co-substrate and the initial mixture for pilot scale experiment (in parenthesis, number of carbon atoms and number of insaturations).

\begin{tabular}{lcccccc}
\hline & Mystiric & Palmitic & Stearic & Oleic & Linoleic & Other \\
& & & & & & \\
& $(\mathrm{C} 14: 0)$ & $(\mathrm{C} 16: 0)$ & $(\mathrm{C} 18: 0)$ & $(\mathrm{C} 18: 1)$ & $(\mathrm{C} 18: 2)$ & LCFA \\
& & & & & & \\
\hline Animal fat & 3.0 & 30.0 & 17.0 & 38.0 & 6.0 & 6.0 \\
\hline Initial mixture & 3.7 & 27.4 & 20.7 & 36.1 & 2.1 & 10.0 \\
& & & & & & \\
\hline
\end{tabular}


Table 3. Initial properties of the mixtures co-composted in laboratory (control experiment; L30, sludge with $30 \%$ of total fat content; and L50, sludge with $50 \%$ of total fat content) and pilot scale (P30) experiments and yields obtained in the composting process.

\begin{tabular}{|c|c|c|c|c|}
\hline \multirow{2}{*}{ Parameter } & \multicolumn{3}{|c|}{ Laboratory scale } & \multirow{2}{*}{$\begin{array}{c}\text { Pilot scale } \\
\text { P30 }\end{array}$} \\
\hline & Control & L30 & L50 & \\
\hline Initial Moisture Content (\%, wet basis) & 55.7 & 48.2 & 35.0 & 54.4 \\
\hline Initial Dry Matter (\%) & 44.3 & 51.8 & 65 & 45.6 \\
\hline Initial Total Organic Matter ( $\%$ dry basis) & 82.7 & 87.2 & 92.6 & 82.9 \\
\hline Initial Fat content ( $\%$ dry basis) & 9.3 & 32.8 & 53.0 & 36.6 \\
\hline Initial N-Kjeldhal (\% dry basis) & 1.2 & 0.9 & 0.5 & 1.2 \\
\hline $\mathrm{C} / \mathrm{N}$ ratio* & 8.0 & 32 & 65 & 28 \\
\hline Initial $\mathrm{pH}$ & 8.1 & 6.7 & 6.2 & 7.6 \\
\hline Dry Weight Reduction (\%) & 13.8 & 39.0 & 36.9 & 41.8 \\
\hline Total Fat Reduction (\%) & 50.2 & 85.3 & 68.5 & 83.4 \\
\hline
\end{tabular}

* not considering wood chips 
Table 4. Stability assays: Respiration Index and Self-heating Test.

\begin{tabular}{ccc}
\hline Day of process & Respiration Index & Self-heating Test \\
& $\left(\mathrm{mg} \mathrm{O}_{2} \mathrm{~g} \mathrm{OM}^{-1} \mathrm{~h}^{-1}\right)$ & (Maturity Grade) \\
\hline 20 & $2.4 \pm 0.1$ & - \\
\hline 32 & $5.2 \pm 2.5$ & - \\
\hline 44 & $1.2 \pm 0.1$ & III \\
\hline 55 & $1.1 \pm 0.1$ & IV \\
\hline 62 & $1.3 \pm 0.2$ & IV \\
\hline 69 & $1.1 \pm 0.1$ & \\
\hline
\end{tabular}




\section{Figure Legends}

Figure 1: Laboratory scale composting: temperature (continuous line), total fat content (squares) and lipolytic activity (circles) for a) control experiment; b) L30; c) L50.

Figure 2: Evolution of the most significant long chain fatty acids in L50: palmitic acid (circles), stearic acid (triangles) and oleic acid (squares).

Figure 3: Composting experiment at pilot scale: a) temperature (continuous line), moisture content (circles) and water additions (triangles); b) oxygen (continuous line), $\mathrm{CO}_{2}$ (dotted line) and respiratory quotient (open squares).

Figure 4: Composting experiment at pilot scale: a) lipolytic activity at $30^{\circ} \mathrm{C}$ (circles) and at $50^{\circ} \mathrm{C}$ (squares); b) total fat content (open circles) and LCFA concentration: palmitic acid (circles), stearic acid (triangles) and oleic acid (squares).

Figure 5: Effect of temperature on lipolytic activity.

Figure 6: Surface response corresponding to lipase stability for different $\mathrm{pH}$ and temperatures.

Figure 7: SDS-PAGE of lipase sample. Lane M: molecular weight standards; Lane 1: lipase sample from P30 experiment (thermophilic period). 
Figure 1: Gea et al.
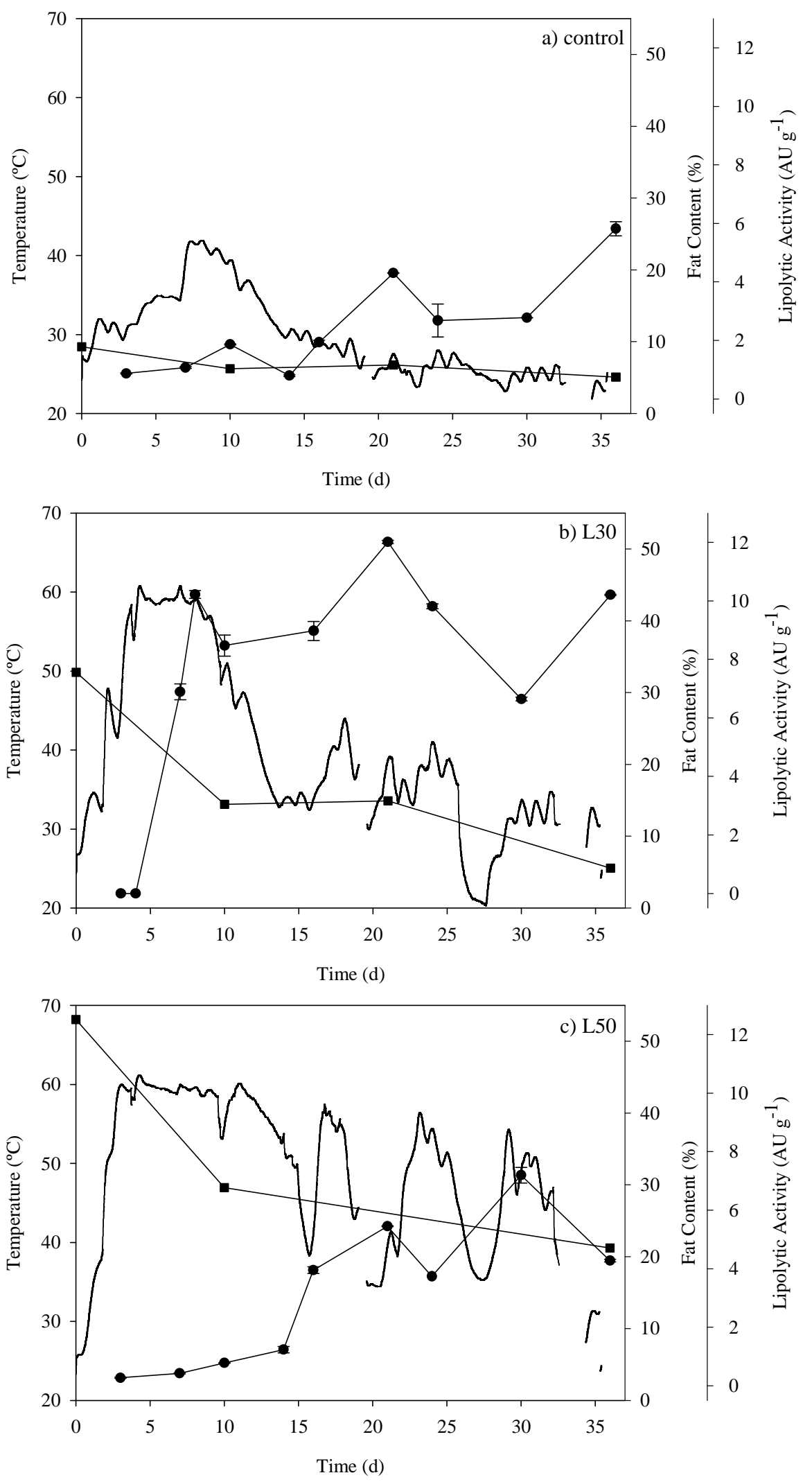
Figure 2: Gea et al.

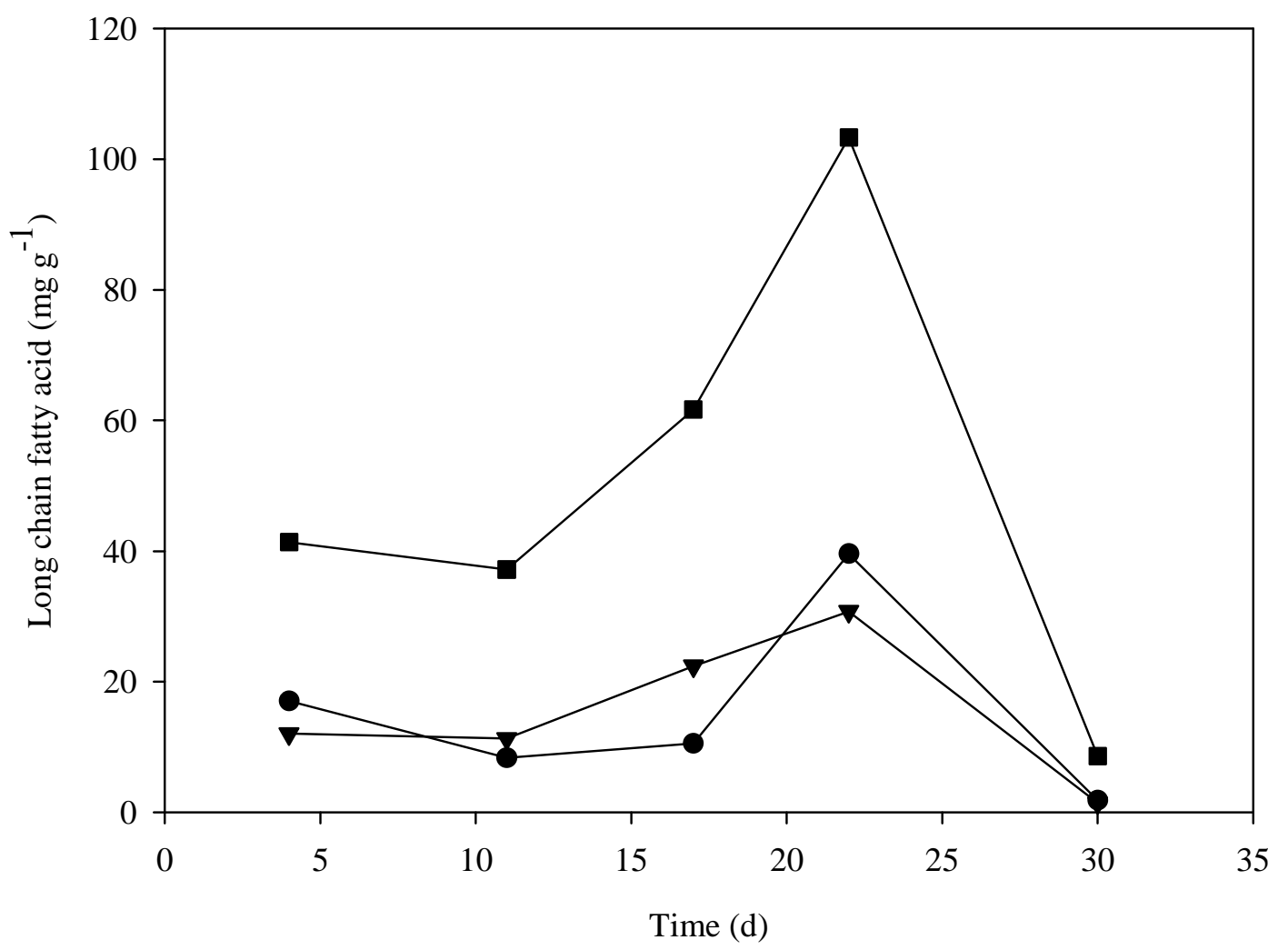


Figure 3: Gea et al.
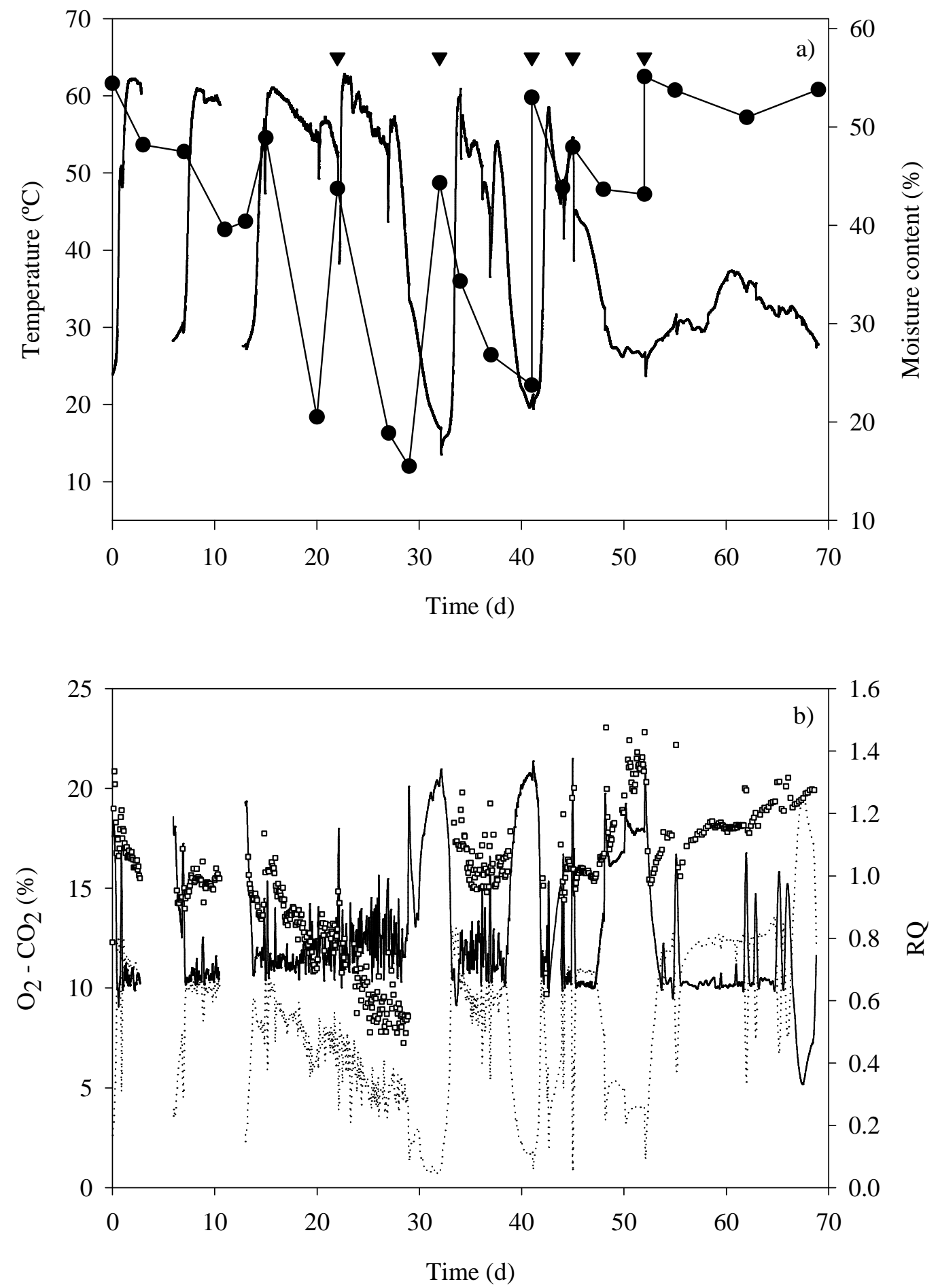
Figure 4: Gea et al.
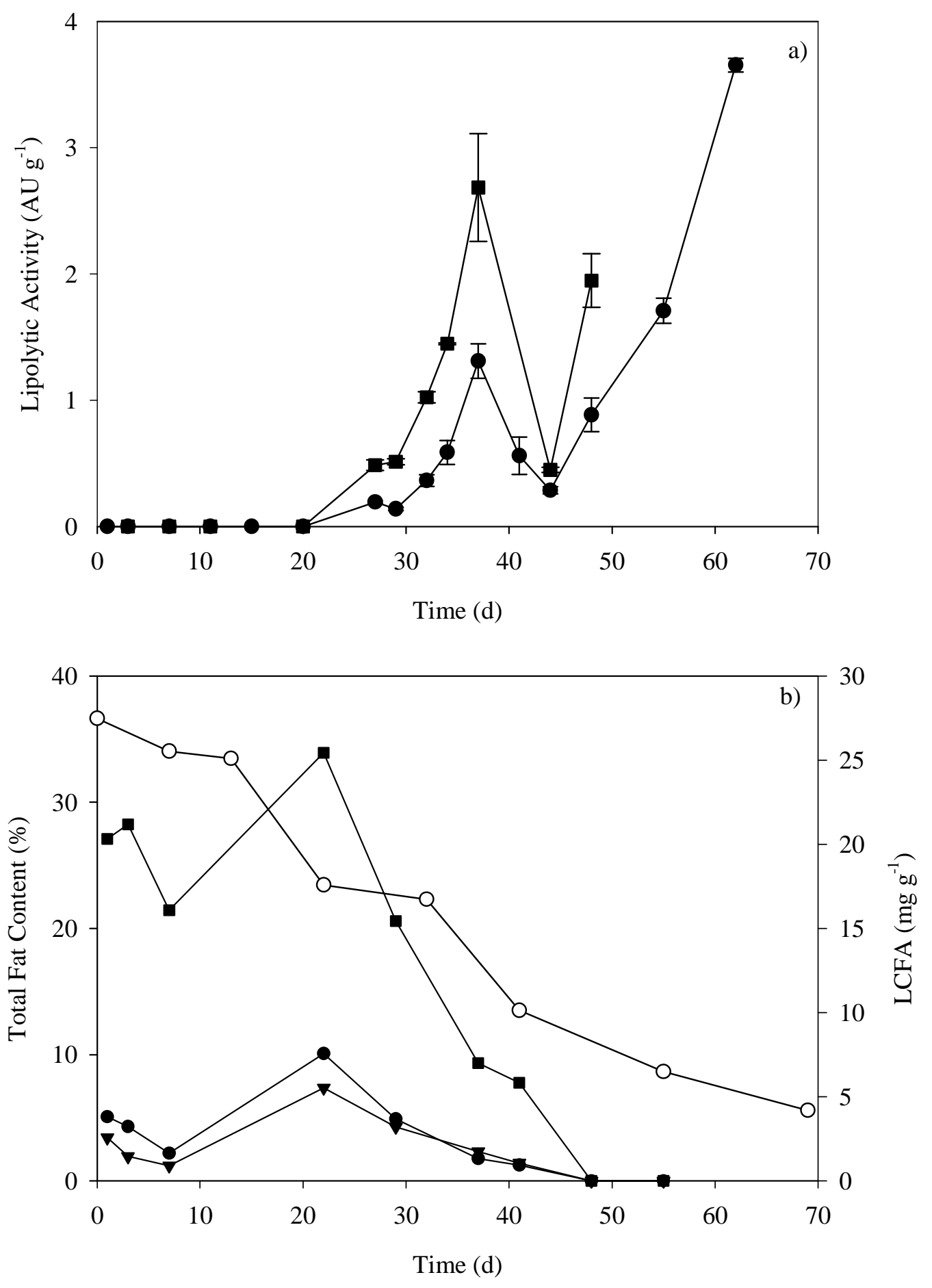
Figure 5: Gea et al.

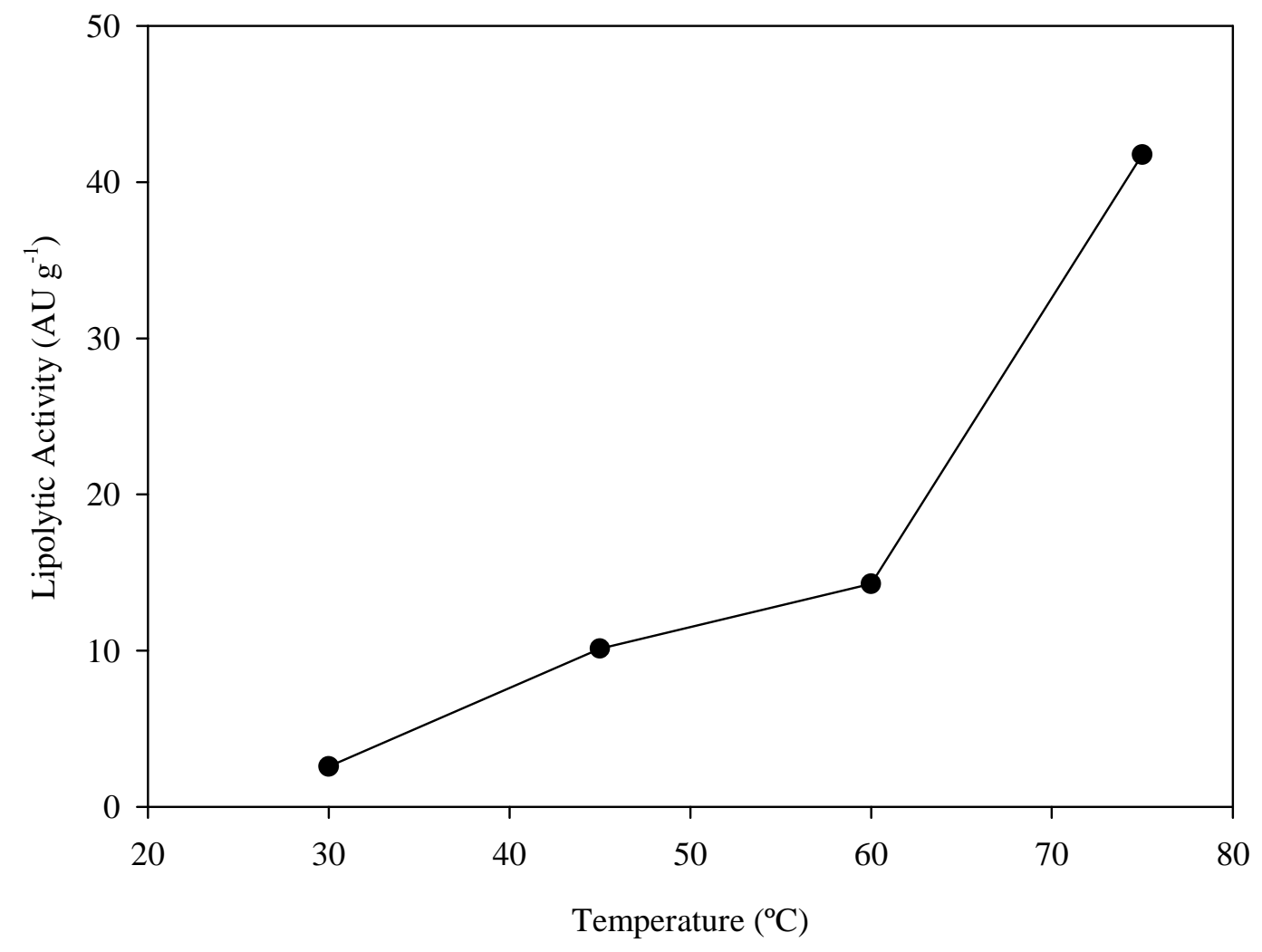




\section{Figure 6: Gea et al.}

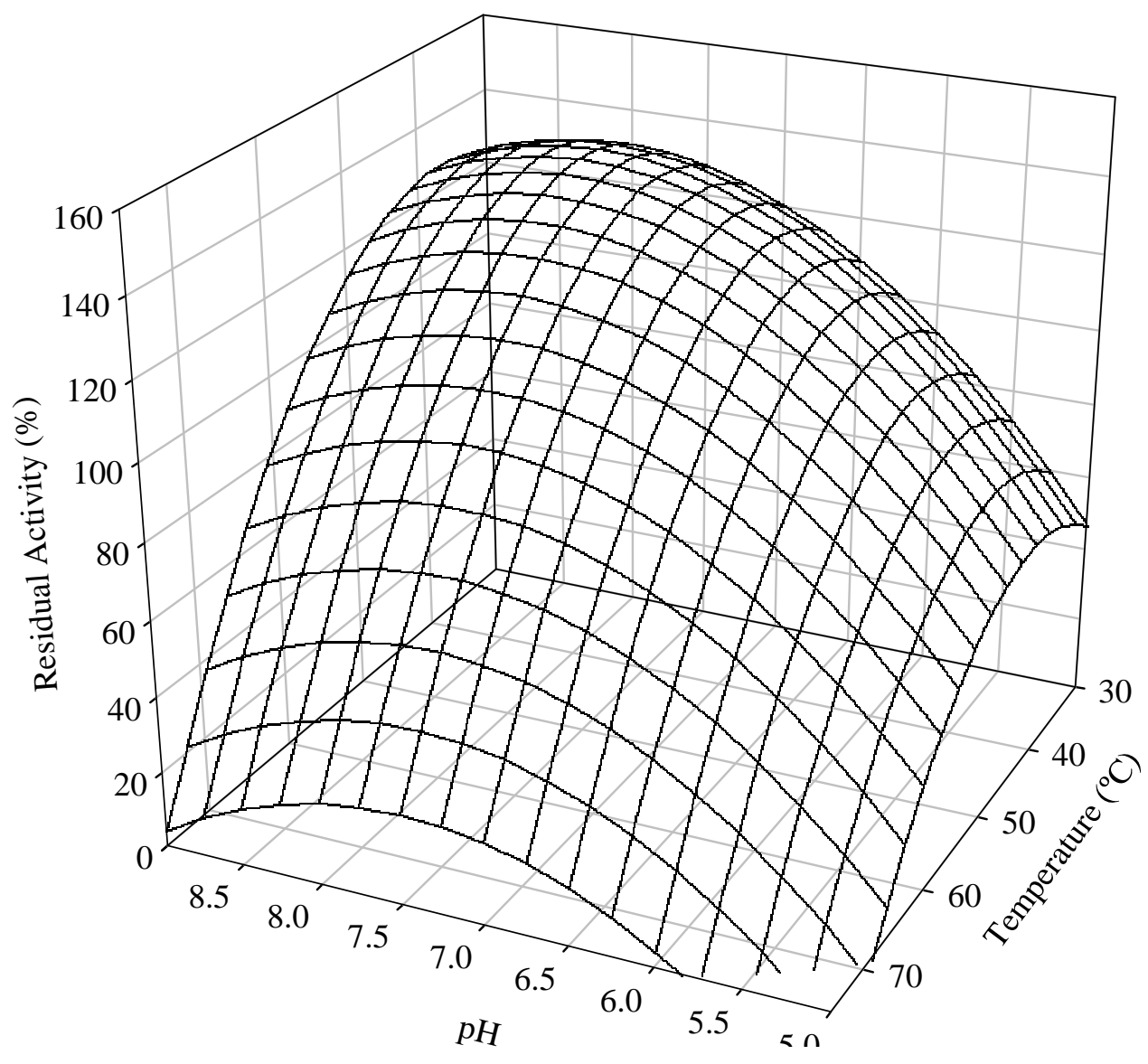


Figure 7: Gea et al.

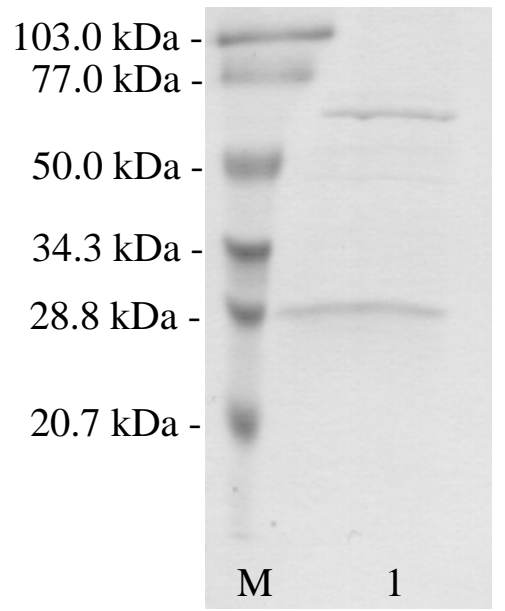

